\title{
Antifungal siderophore conjugates for theranostic applications in invasive pulmonary aspergillosis using low molecular TAFC scaffolds
}

\author{
Joachim Pfister ${ }^{1}$, Milos Petrik ${ }^{2}$, Katerina Bendova ${ }^{2}$ Barbara Matuszczak $^{3}$, Ulrike Binder ${ }^{4}$, Alexander \\ Kühbacher ${ }^{5}$, Fabio Gsaller ${ }^{5}$, Matthias Misslinger ${ }^{5}$ Hubertus Haas ${ }^{5}$ and Clemens Decristoforo ${ }^{1, *}$ \\ 1 Department of Nuclear Medicine, Medical University Innsbruck; joachim.pfister@i-med.ac.at (J.P.) \\ 2 Institute of Molecular and Translational Medicine, Faculty of Medicine and Dentristry, Palacky University Olomouc, \\ 772-00 Olomouc, Czech Republic; milos.petrik@upol.cz (M.P.) katerina.bendova01@upol.cz (K.M.) \\ 3 Institute of Pharmacy/Pharmaceutical Chemistry, University of Innsbruck; Barbara.matuszczak@uibk.ac.at (B.M) \\ 4 Institute of Hygiene \& Medical Microbiology, Medical University of Innsbruck, Austria ulrike.binder@i-med.ac.at \\ (U.B.) \\ 5 Instiute of Molecular Biology, Medical University Innsbruck, Innsbruck, Austria; alexander.kuehbacher@i-med.ac.at \\ (A.K); fabio.gsaller@i-med.ac.at (F.G.); matthias.misslinger@i-med.ac.at (M.M.) hubertus.haas@i-med.ac.at (H.H.) \\ * Correspondence: Clemens.decristoforo@i-med.ac.at; Tel.: +43-512-504-80951 (C.D.)
}

\begin{abstract}
:
Invasive pulmonary aspergillosis (IPA) is a life-threatening form of fungal infection, primarily in immunocompromised patients and associated with a significant mortality. Diagnostic procedures are often invasive and/or time consuming and existing antifungals can be constrained by dose limiting toxicity and drug interaction. In this study, we modified triacetylfusarinine C (TAFC), the main siderophore produced by the opportunistic pathogen Aspergillus fumigatus, with antifungal molecules to perform antifungal susceptibility tests and molecular imaging.

Methods: A variation of small organic molecules (eflornithine, fludioxonil, thiomersal, fluoroorotic acid (FOA), cyanine 5 (Cy5)) with antifungal activity were coupled to TAFC, resulting in a "Trojan horse" to deliver antifungal compounds specifically into Aspergillus fumigatus hyphae by the major facilitator transporter MirB. Radioactive labelling with gallium-68 allowed to perform in vitro characterization (LogD, stability, uptake assay) as well as biodistribution experiments and PET/CT imaging in an IPA rat infection model. Compounds labelled with stable gallium were used for antifungal susceptibility tests.

Results: [Ga]DAFC-fludioxonil, -FOA and Cy5 revealed a MirB dependent active uptake with fungal growth inhibition at $16 \mu \mathrm{g} / \mathrm{mL}$ after $24 \mathrm{~h}$. Visualization of an Aspergillus fumigatus infection in lungs of a rat was possible with gallium-68 labelled compounds using PET/CT. Heterogeneous biodistribution patterns revealed the immense influence of the antifungal moiety conjugated to DAFC. Conclusion: Overall, novel antifungal siderophore conjugates with promising fungal growth inhibition and the possibility to perform PET-imaging, combine both therapeutic and diagnostic potential in a theranostic compound for IPA caused by Aspergillus fumigatus.
\end{abstract}

Keywords: Siderophore; TAFC; antifungal; invasive pulmonary aspergillosis; Aspergillus fumigatus, antifungal susceptibility testing; PET/CT, theranostics 


\section{Introduction}

Invasive aspergillosis (IA) is a severe infection in humans, associated with high mortality and an estimated incidence of 250,000 cases a year worldwide [1,2]. IA most commonly involves the lungs resulting in invasive pulmonary aspergillosis (IPA) in immunocompromised patients with Aspergillus fumigatus (A. fumigatus) as the most common opportunistic pathogen involved [3,4].

Diagnostic procedures recommended by current guidelines [5] are often invasive (e.g. bronchoalveolar lavage, bronchoscopy) and/or time consuming, worsen survival outcome for patients $[2,6]$. Current treatment options are azoles, echinocandins and polyenes [5,7] but antifungal resistance is a concern for the management of A. fumigatus infections [8]. Furthermore, antifungal agents are often constrained by drug interaction, route of administration and dose-limiting toxicity. These factors are very alarming and demand for a continuous improvement in the diagnosis and treatment of IPA.

During infection, the human body sequesters iron as a defense strategy to prevent growth of pathogens [9]. Iron is an essential micronutrient and A. fumigatus has developed sophisticated strategies to overcome this problem: low-affinity iron uptake, reductive iron assimilation (RIA) and siderophoremediated iron acquisition (SIA) [10] whereby RIA and SIA are high-affinity iron uptake systems. SIA is highly upregulated during infection and essential for the virulence of A. fumigatus [11]. Siderophores are low-molecular mass organic molecules with a high affinity to bind ferric iron ( $\mathrm{Fe}(\mathrm{III})$ ). A. fumigatus produces different types of siderophores: desferry-fusarinine $\mathrm{C}$ (FsC) and desferry-triacetylfusarinine $\mathrm{C}$ (TAFC) for external iron acquisition and desferri-ferricrocin, desferri-hydroxy-ferricrocin for internal iron storage [12]. After binding iron in the environment, [Fe]TAFC is taken up by the hyphae with a specific transporter called MirB [13]. This transporter is highly upregulated during infection [11] and additionally, [Fe]TAFC shows a very high specificity for A. fumigatus lacking uptake by mammalian cells $[14,15]$. This offers an opportunity to use MirB as a target for imaging and treatment of $A$. fumigatus infections.

Petrik et al. showed the possibility of exchanging iron from $[\mathrm{Fe}] \mathrm{TAFC}$ with the radioactive isotope gallium-68 to perform PET/CT imaging in an lung infection animal model [16]. Furthermore, by using diacetylfusarinine $\mathrm{C}([\mathrm{Fe}] \mathrm{DAFC})$, which possesses a free amine group, chemical modifications are possible [17]. In previous experiments by our group, we used fluorescent dyes coupled to DAFC to perform fluorescence-microscopy of A. fumigatus hyphae [18] and labelled with gallium-68, hybrid imaging of an infection in a rat model [19]. This proof of principle using TAFC as a "Trojan horse" to channel a variety of molecules specifically into A. fumigatus via the MirB transporter, led us to the idea to adopt this system for antifungal molecules. For this purpose, different candidates (Figure 1) were chosen depending on certain, individual properties.

Eflornithine, an inhibitor of ornithine decarboxylase [20], is a very multifunctional drug as it is used topically (15\% eflornithine cream) against unwanted facial hair (hirsutism) [21], as a treatment for malignant gliomas [22] and as intravenous cocktail in combination with nifurtimox, approved by the EMA against African trypanosomiasis (sleeping sickness) caused by Trypanosoma brucei gambiense $[23,24]$. Beckmann et al. showed an antifungal activity against $A$. fumigatus in agar diffusion assays [25], which potentially could be enhanced by active transport into the hyphae via MirB. The same rational was applied for fluoroorotic acid, which is converted by ornithine-5'-monophosphate (OMP)decarboxylase to the toxic intermediate 5-fluoro-UMP, commonly used for selection in yeast genetic experiments [26]. Furthermore, we chose fludioxonil, a phenylpyrrole pesticide used post-harvest for fruit and vegetable crops to minimize losses from mold contamination during transport and point of sale. It inhibits class III hybrid histidine kinases (HHK) that are peculiar to fungi and regulate the high osmolarity glycerol pathway (HOG) [27]. For the last 30 years it has been postulated to be safe for human as there is no target in the body, but studies are currently ongoing to investigate if there are adverse health effects on the cellular level [28]. By coupling fludioxonil to DAFC, the active uptake by MirB could lower the administered dosage needed and interaction with human targets could be hindered by this modification. A similar concept could be applied for thiomersal which was commonly used as a preservative substance in vaccines and ophthalmic products [29,30] but adverse health effects of ethylmercury (active metabolite) are still controversially discussed [31]. The last compound Cy5 was 
originally designed as an agent for hybrid imaging and microscopy, whereby an antifungal activity was observed during growth experiments by our group $[18,19]$.

The aim of the study was to investigate the growth inhibition potential of various antifungal siderophore conjugates and to visualize an A. fumigatus lung infection via PET/CT in a rat model by labelling the compounds with gallium-68. Thereby, beside antifungal properties also pharmacokinetic differences of individual compounds were revealed, providing essential data for further applications aiming at MirB as a drug target. This proof of principle shows the possibility of using these compounds for therapy and diagnostic with the same molecule, in a so called theranostic approach.

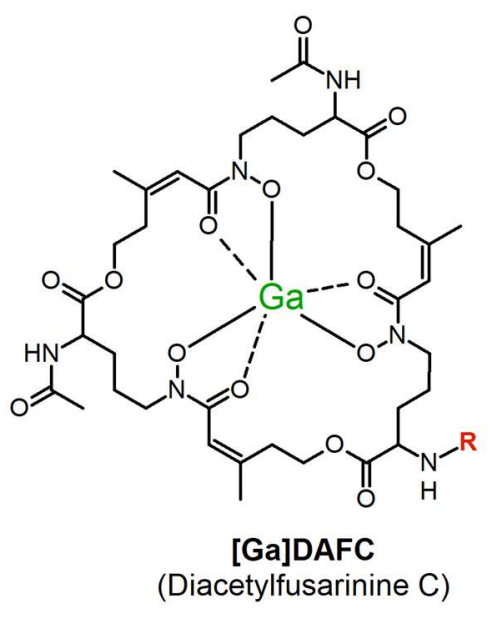

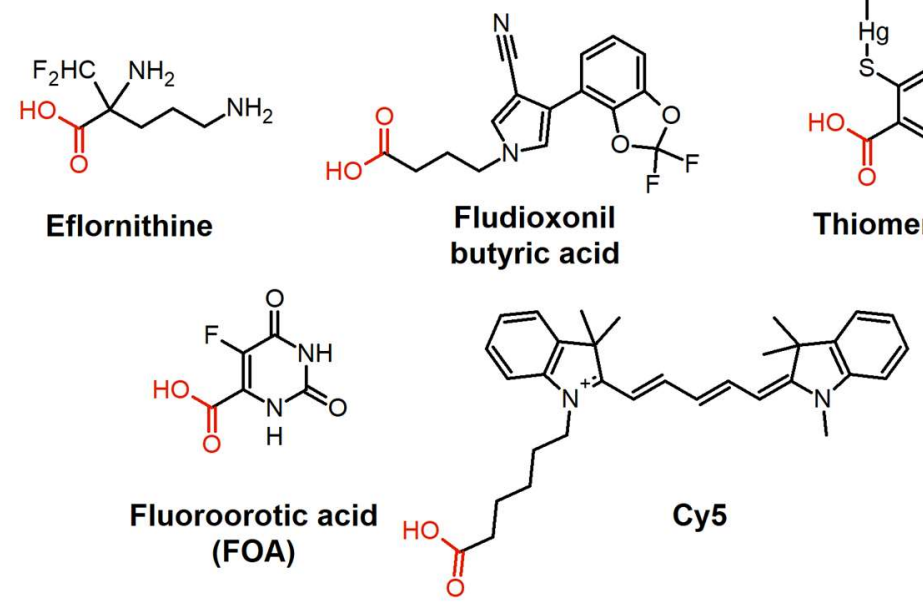

Figure 1. Chemical structures of antifungal compounds used in this study. On the left side: gallium labelled form of diacetylfusarinine $\mathrm{C}$ (DAFC); red part of the structures indicate coupling site of individual molecules.

\section{Materials and Methods}

\subsection{Chemicals and Synthesis of Antifungal conjugates}

All chemicals were purchased from Sigma Aldrich as reagent grade and used without further purification unless stated otherwise. Exact synthetic procedures and analytical details can be found in the supplementary material. Starting from iron containing diacetylfusarinine C ([Fe]DAFC) all antifungal conjugates were conjugated forming an amide bond using O-(7-Azabenzotriazol-1-yl)$\mathrm{N}, \mathrm{N}, \mathrm{N}^{\prime}, \mathrm{N}^{\prime}$-tetramethyluronium hexafluorophosphate (HATU) as an activating reagent. To couple eflornithine, free amino groups in the molecular structure had to be protected with tert-butyloxycarbonyl (Boc) before linking with [Fe]DAFC followed by cleavage of the Boc protecting groups with trifluoroacetic acid. fludioxonil had to be modified with ethyl 4-bromobutyrate resulting in a new compound with an ester function, followed by hydrolysis to get the free free carboxylic acid, suitable for HATU coupling.

All siderophore conjugates were purified by preparative HPLC and freeze dried. For iron removal, compounds were incubated with $100 \mathrm{mM} \mathrm{Na}_{2}$ EDTA solution and subsequently purified by preparative HPLC, resulting in the iron free form for radiolabelling experiments. Stable gallium containing siderophore conjugates were produced by coupling the antifungal directly to [Ga]DAFC to reduce iron contamination to a minimum. Exact coupling conditions and a detailed description can be found in the supplementary material as well as analytical data for each compound, respectively. 


\section{Radiolabelling}

Gallium-68 was produced by fractionated elution of ${ }^{68} \mathrm{Ge} /{ }^{68} \mathrm{Ga}$-generator (IGG100. Eckert \& Ziegler Isotope Products, Berlin, Germany; nominal activity of $1850 \mathrm{MBq}$ ) with 0.1 M hydrochloric acid (HCL, Rotem Industries, Arva, Israel). For labelling, $10 \mu \mathrm{g}(5-8 \mathrm{nmol})$ of DAFC-conjugate were mixed with $200 \mu \mathrm{L}$ gallium eluate ( 15-30 MBq) and the $\mathrm{pH}$ was adjusted to 4.5 by adding $20 \mu \mathrm{L}$ of sodium acetate solution $(1.14 \mathrm{M})$ per $100 \mu \mathrm{L}$ eluate. The mixture was left to react for $10 \mathrm{~min}$ at RT and finally analyzed by radio-TLC and radio-RP-HPLC [32].

\section{In Vitro Experiments}

\section{Distribution Coefficient $(\log D)$}

To determine the lipophilicity of the conjugates, the distribution coefficient between octanol and PBS buffer was determined. Radiolabelled compounds were dissolved in PBS to a concentration of approximately $9 \mu \mathrm{M}$ and $50 \mu \mathrm{L}$ of this solution was added to $450 \mu \mathrm{L}$ PBS and $500 \mu \mathrm{L}$ octanol into an eppendorf tube. The two phases were vigorously shaken for $20 \mathrm{~min}$ at $1400 \mathrm{rpm}$ at room temperature (MS 3 basic vortexer, IKA, Staufen, Germany) followed by centrifugation for 2 min at $4500 \mathrm{rpm}$ (Eppendorf Centrifuge 5424, Eppendorf AG, Hamburg, Germany).

Hereafter, $200 \mu \mathrm{L}$ of each phase were collected and measured in a 2480 automatic Gamma counter Wizard 2 3" (PerkinElmer, Waltham, MA, USA). LogD value were calculated using Excel by dividing measured values of octanol by water and logarithmize the result. Values $>0$ reflects lipophilic-, values $<0$ hydrophilic compounds. ( $\mathrm{n}=3$, six technical replicates)

\section{Protein Binding}

For this procedure siderophore conjugates were labelled as described before and diluted with PBS to a concentration of approximately $9 \mu \mathrm{M} .50 \mu \mathrm{L}$ of this solution were added to $450 \mu \mathrm{L}$ of PBS (control) or $450 \mu \mathrm{L}$ of fresh human serum and incubated at $37^{\circ} \mathrm{C}$ for 30,60 and 120 minutes. At each timepoint, $25 \mu \mathrm{L}$ of PBS/serum were analyzed by size exclusion chromatography using MicroSpin G-50 columns (Sephadex G-50, GE Healthcare, Vienna, Austria) according to the manufacturer's protocol. Hereafter, the column and eluate were measured separately in the gamma counter and percentage of protein bound conjugate was calculated by dividing measured counts of eluate by total counts. Radioactivity in the eluate reflects protein bound fraction and column bound, free labelled siderophore conjugate. $(n=3$, three technical replicates)

\section{Serum Stability}

Serum stability probes were prepared according to protein binding section with PBS and fresh human serum. After 60,120 and 240 minutes, $70 \mu \mathrm{L}$ of serum/PBS were mixed with $70 \mu \mathrm{L}$ of acetonitrile to precipitate proteins in the serum. Hereafter, the mixture was centrifuged for 1 minute and $70 \mu \mathrm{L}$ of the supernatant were diluted with water and analyzed by radio-HPLC to determine intact labelled siderophore conjugate. $(n=2$, two technical replicates)

\section{Uptake and Competition Assay}

Uptake assays were performed as previously described [17]. Briefly, $180 \mu \mathrm{L}$ of A. fumigatus culture in iron-depleted and iron-replete (control - transporter suppression) aspergillus minimal media (AMM) [33] were added in pre-wetted 96-well MultiScreen Filter Plates HTS (1 $\mu \mathrm{m}$ glass fiber filter, Merck Millipore, Darmstadt, Germany) and incubated for $15 \mathrm{~min}$ at $37^{\circ} \mathrm{C}$ with either $25 \mu \mathrm{L}$ PBS or $25 \mu \mathrm{L}$ [Fe]TAFC solution (control - uptake block; $\sim 10 \mu \mathrm{M}$ ). Hereafter, $50 \mu \mathrm{L}$ of radiolabelled compound (final concentration approximately $90 \mathrm{nM}$ ) was added and incubated for another $45 \mathrm{~min}$ at $37^{\circ} \mathrm{C}$. Hyphae were washed two times with ice-cold TRIS buffer and dry filters were measured in the gamma counter.

Competition assays were performed in the same way with slight modifications. Fungal cultures were pre-incubated with iron-labelled siderophore conjugates for $15 \mathrm{~min}$ (similar to blocking) and uptake values of $\left[{ }^{68} \mathrm{Ga}\right] \mathrm{Ga}-\mathrm{TAFC}$ into hyphae was determined after $45 \mathrm{~min}$ of incubation. 


\section{Growth Promotion Assay}

This procedure was performed as previously described [34]. In this assay a mutant strain of $A$. fumigatus ( $\triangle$ sidA/AftrA) that lacks the genes sidA and ftrA was used. These mutations impair both siderophore biosynthesis and reductive iron acquisition (RIA), in other words endogenous high-affinity iron acquisition [11], however this mutant is still able to take up siderophores. Consequently, utilization of siderophores can be simply tested by growth promotion assays allowing to analyze the effect of siderophore modification compared to the original molecule such as [Fe]TAFC In case of growth reduction distinction between reduced iron-utilization and antifungal activity is not possible. Conidia $\left(10^{4}\right)$ were point inoculated on solid $0.5 \mathrm{~mL}$ of iron depleted AMM in 24-well plates containing increasing concentrations of iron-labelled siderophore ranging from $0.1-50 \mu \mathrm{M}$. Plates were incubated for $48 \mathrm{~h}$ at $37^{\circ} \mathrm{C}$ in a humidity chamber and visually assessed[19]. $(\mathrm{n}=3$, three biological replicates)

\section{Antifungal Susceptibility Assays}

Antifungal susceptibility assays were performed with 96-well flat bottom plates (Greiner Bio-One $\mathrm{GmbH})$ prepared with $100 \mu \mathrm{L}$ of iron-depleted $[\mathrm{Fe}(-)]$ and -replete $[\mathrm{Fe}(+)] 2 \times \mathrm{AMM}$ containing $3 * 10^{4}$ spores of A. fumigatus (ATCC 46645) per well.

$100 \mu \mathrm{L}$ of antifungal siderophore conjugate, dissolved in water, was added to get a final concentration of $1 \times$ AMM and siderophore conjugates in serial 2-fold dilutions in concentrations ranging from $256-0.016 \mu \mathrm{g} / \mathrm{mL}$. Minimal inhibitory concentration (MIC) value was defined as the lowest concentration resulting in no visible fungal growth after $24 \mathrm{~h}$ and $48 \mathrm{~h}$ incubation at $37^{\circ} \mathrm{C}$ in a humidity chamber. Assays were repeated three times as biological replicates $(\mathrm{n}=3)$.

Results were also displayed by taking microscopy pictures of each well after $24 \mathrm{~h}$. Images were acquired with the IncuCyte S3 Live-Cell Analysis System equipped with a 20x magnification S3/SX1 G/R Optical Module (Essen BioScience Inc.). From each well a representative image was taken from the center of the well. Fungal growth was analyzed using the Basic Analyzer tool (Confluence \%; Segmentation adjustment: 0; Adjust Size: 0) of the IncuCyte S3 software (Version 2019; Essen Bioscience Inc.). Images and confluence mask were exported in raw 8-bit images and raw 8-bit confluence mask, respectively. An overview of these pictures can be seen in the supplementary material. (Figure S3 and S4)

\section{Animal experiments}

All animal experiments were conducted in compliance with the Austrian Animal Protection laws and with approval of the Austrian Ministry of Science (BMWFW-66.011/0161-WF/V/3b/2016), the Czech Ministry of Education Youth and Sports (MSMT-21275/2016-2) and the institutional Animal Welfare Committee of the Faculty of Medicine and Dentistry of Palacky University in Olomouc.

\section{In Vivo Stability and Ex Vivo Biodistribution}

Stability test and biodistribution were conducted in 4-6 weeks old female BALB/c mice (in-house breed, ZVTA Innsbruck). ${ }^{68}$ Ga-labelled conjugates were injected via lateral tail vein using approximately $0.4 \mathrm{nmol}$ of siderophore conjugate.

In vivo stability was determined by radio-HPLC analysis. After injection of the radiolabelled compound $(\sim 12 \mathrm{MBq})$ the mouse was euthanized after 10 minutes by cervical dislocation. Blood was collected and precipitated with ACN to remove proteins. Subsequently, the supernatant was diluted with water and used for further analysis. Urine samples were directly injected into the radio-HPLC. Percentage of intact radiolabelled siderophore conjugate was calculated by integration of the radiochromatogram $(n=2)[35]$.

For biodistribution a similar procedure was applied but the mice were euthanized at 45 and 90 minutes. Hereafter, organs (blood, spleen, pancreas, stomach, liver, kidneys, heart, lung, muscle, femur) were removed and weighted. Samples were measured in a gamma counter and results expressed as percentage of injected dose per gram tissue $(\% \mathrm{ID} / \mathrm{g}) .(\mathrm{n}=3)$ 
bioRxiv preprint doi: https://doi.org/10.1101/2021.04.19.440472; this version posted April 19, 2021. The copyright holder for this preprint (which was not certified by peer review) is the author/funder, who has granted bioRxiv a license to display the preprint in perpetuity. It is made available under aCC-BY-NC-ND 4.0 International license.

\section{Invasive Pulmonary Aspergillosis Model in Rats}

2-3 months old female Lewis rats were treated with the immunosuppressant cyclophosphamide (Endoxan, Bayter, $75 \mathrm{mg} / \mathrm{kg}$ i.p.) 5 days and 1 day before infected with A. fumigatus, to induce neutropenia. The animals received repeatedly ( 5 days, 1 day before and on the day of inoculation) antibiotic teicoplanin (Targocid, Sanofi, $35 \mathrm{mg} / \mathrm{kg}-5$ days before i.m. or $25 \mathrm{mg} / \mathrm{kg}$ i.m. -1 day before and on the day of inoculation) to avoid bacterial superinfections and additional antibiotics were administered by drinking water (Ciprofloxacin, $2 \mathrm{mM}$, Polymyxin E, Colomycin, $0.1 \mathrm{mM}$ ) for the duration of the experiment. Infection in the lung was established by intratracheal inoculation of $100 \mu \mathrm{L}$ of A. fumigatus spores $\left(10^{9} \mathrm{CFU} / \mathrm{mL}\right.$ A. fumigatus $\left.1059 \mathrm{CCF}\right)$ using TELE PACK VET X LED system equipped with a flexible endoscope (Karl Stroz GmbH \& Co. KG, Tuttlingen, Germany) only [36].

\section{PET/CT Imaging}

In vivo PET/CT were conducted after 2-4 days, depending on the health condition of the animal and images were acquired with an Albira PET/SPECT/CT small animal imaging system (Bruker Biospin Corporation, Woodbridge, CT, USA). Radiolabelled antifungal siderophore conjugates were administered by retro-orbital (r.o.) injection of $5-10 \mathrm{MBq}$ dose corresponding to $\sim 2 \mu \mathrm{g}$ of DAFCconjugate per female Lewis rat.

Animals were anaesthetized with isoflurane (Forene ${ }^{\circledR}$, Abbott Laboratories, Abbott Park, IL, USA) ( $2 \%$ flow rate) and positioned prone headfirst in the Albira system before the start of imaging. Static PET/CT imaging was carried out 45 min p.i. for all tested compounds. Infected animals were imaged three days after the inoculation with A. fumigatus spores. A 10-min PET scan (axial FOV $148 \mathrm{~mm}$ ) was performed, followed by a triple CT scan (axial FOV $3 \times 65 \mathrm{~mm}, 45 \mathrm{kVp}, 400 \mu \mathrm{A}$, at 400 projections). Scans were reconstructed with the Albira software (Bruker Biospin Corporation, Woodbridge, CT, USA) using the maximum likelihood expectation maximization (MLEM) and filtered backprojection (FBP) algorithms. After reconstruction, acquired data were viewed and analyzed with PMOD software (PMOD Technologies Ltd., Zurich, Switzerland).

\section{Results}

\section{Synthesis and Radiolabelling}

Precursor preparation of eflornithine by shielding the free amino groups with Boc-protection was obtained in moderate yield ( $>20 \%$, non-optimized) but suitable for conjugation to [Fe]/[Ga]DAFC with standard HATU coupling. Synthesis of fludioxonil-butyric acid was carried out using a two-step reaction, which involved $\mathrm{N}$-alkylation of the pyrrole with ethyl 4-bromobutyrate and followed by basic hydrolysis of ethyl ester group. Hereafter, the free carboxylic acid could easily couple to the $[\mathrm{Fe}] /[\mathrm{Ga}] \mathrm{DAFC}$ siderophore with very good yields over $60 \%$. All other conjugates were directly linked by our standard HATU coupling strategy with yields of $20-80 \%$. Exact analytical data are provided in the supplementary material.

Radiolabelling of all compounds was achieved with almost quantitative radiochemical yields $(>95 \%)$ in 10 minutes at room temperature. Labelled compounds were used without any further purification.

\section{In Vitro Characterization}

\section{LogD, Protein Binding and Serum Stability}

Distribution coefficient $(\log D)$, protein binding and serum stability in fresh human serum of all siderophore conjugates are summarized in Table 1. Log D values ranging from -3.45 to 1.30 revealed heterogeneous solubility properties of conjugated antifungals compared to $\log \mathrm{D}$ of the precursor molecule [Fe]DAFC with -2.34 [17]. 
bioRxiv preprint doi: https://doi org/10.1101/2021.04.19.440472; this version posted April 19, 2021. The copyright holder for this preprint (which was not certified by peer review) is the author/funder, who has granted bioRxiv a license to display the preprint in perpetuity. It is made available under aCC-BY-NC-ND 4.0 International license.

Protein binding revealed overall low and consistent values over time, except for $\left[{ }^{68} \mathrm{Ga}\right] \mathrm{Ga}-\mathrm{DAFC}-$ thiomersal which was $\sim 70 \%$. Compared to $\left[{ }^{68} \mathrm{Ga}\right] \mathrm{Ga}$-DAFC-FOA with an even higher $\operatorname{LogD}$ of 1.3 but lower protein binding ( $\sim 4 \%$ ), this could be explained by the reduced serum stability of $\left[{ }^{68} \mathrm{Ga}\right] \mathrm{Ga}-\mathrm{DAFC}$ thiomersal which was $\sim 80 \%$.

Table 1. Distribution coefficient, protein binding and serum stability of siderophore compounds radiolabelled with gallium- 68 . Values of serum stability reflect percentage of intact radiolabelled conjugate. Results reflects three individual experiments; (*) Data from [19]

\begin{tabular}{|c|c|c|c|c|c|c|}
\hline & & $\begin{array}{c}{\left[{ }^{68} \mathrm{Ga}\right] \mathrm{Ga}-\mathrm{DAFC}-} \\
\text { eflornithine }\end{array}$ & $\begin{array}{c}{\left[{ }^{68} \mathrm{Ga}\right] \mathrm{Ga}-\mathrm{DAFC}-} \\
\text { fludioxonil }\end{array}$ & $\begin{array}{c}{\left[{ }^{68} \mathrm{Ga}\right] \mathrm{Ga}-\mathrm{DAFC}-} \\
\text { thiomersal }\end{array}$ & $\begin{array}{l}{\left[{ }^{68} \mathrm{Ga}\right] \mathrm{Ga}-} \\
\text { DAFC-FOA }\end{array}$ & $\begin{array}{c}{\left[{ }^{68} \mathrm{Ga}\right] \mathrm{Ga}-\mathrm{DAFC}-} \\
\mathrm{Cy} 5^{*}\end{array}$ \\
\hline $\begin{array}{l}\text { Distribution } \\
\text { coefficient }\end{array}$ & $\begin{array}{c}\log \mathrm{D} \\
(\mathrm{pH} 7.4)\end{array}$ & $-3.45 \pm 0.04$ & $1.30 \pm 0.02$ & $0.25 \pm 0.06$ & $-2,66 \pm 0.01$ & $1.03 \pm 0.10$ \\
\hline \multirow{3}{*}{$\begin{array}{c}\text { Protein } \\
\text { binding [\%] }\end{array}$} & $30 \mathrm{~min}$ & $11.4 \pm 4.8$ & $14.6 \pm 4.3$ & $67.4 \pm 2.7$ & $2.4 \pm 0.4$ & $13.7 \pm 2.9$ \\
\hline & $60 \mathrm{~min}$ & $8.8 \pm 0.7$ & $16.8 \pm 5.1$ & $71.1 \pm 0.8$ & $2.6 \pm 0.7$ & $13.1 \pm 2.3$ \\
\hline & $120 \mathrm{~min}$ & $10.1 \pm 1.9$ & $15.0 \pm 2.6$ & $68.2 \pm 1.2$ & $3.3 \pm 1.1$ & $13.7 \pm 1.8$ \\
\hline \multirow{3}{*}{$\begin{array}{l}\text { Serum } \\
\text { stability }\end{array}$} & $60 \mathrm{~min}$ & $98 \%$ & $96 \%$ & $72 \%$ & $98 \%$ & $99 \%$ \\
\hline & $120 \mathrm{~min}$ & $99 \%$ & $95 \%$ & $87 \%$ & $98 \%$ & $97 \%$ \\
\hline & $240 \mathrm{~min}$ & $99 \%$ & $95 \%$ & $80 \%$ & $99 \%$ & $97 \%$ \\
\hline
\end{tabular}

Data are presented as mean \pm SD.

\section{Uptake and Competition Assay}

Uptake and competition assays are summarized in Figure 2. Data of DAFC-conjugates are normalized to $\left[{ }^{68} \mathrm{Ga}\right] \mathrm{Ga}-\mathrm{TAFC}$ value of each experiments, respectively, to minimize biological variance. Uptake blocking by [Fe]TAFC results in a competition at the MirB transporter and should decrease the uptake. Under iron-replete conditions, MirB transporter is repressed at transcriptional level [37] and therefore the "uptake" under this condition represents unspecific uptake. All compounds showed reasonable values, i.e. although not as pronounced as found for $\left[{ }^{68} \mathrm{Ga}\right] \mathrm{Ga}-\mathrm{TAFC}$, except for $\left[{ }^{68} \mathrm{Ga}\right] \mathrm{Ga}-$ DAFC-Cy5 with very high unspecific binding in comparison to $\left[{ }^{68} \mathrm{Ga}\right] \mathrm{Ga}-\mathrm{TAFC}$, which could not be reduced during blocking and iron-sufficient conditions. $\left[{ }^{68} \mathrm{Ga}\right] \mathrm{Ga}-\mathrm{DAFC}$-fludioxonil revealed also higher values than $\left[{ }^{68} \mathrm{Ga}\right] \mathrm{Ga}-\mathrm{TAFC}$ but uptake reduction was possible by blocking and even more under iron-replete conditions indicating MirB-dependent uptake. $\left[{ }^{68} \mathrm{Ga}\right] \mathrm{Ga}-\mathrm{DAFC}$-eflornithine, -thiomersal and -FOA showed a similar pattern, however, eflornithine unveiled only $20 \%$ uptake.

In the ferric form, all conjugates were able to block uptake of $\left[{ }^{68} \mathrm{Ga}\right] \mathrm{Ga}$-TAFC in competition experiments, confirming interaction with the MirB transporter. All compounds showed comparable or even better blocking values compared to [Fe]TAFC. 


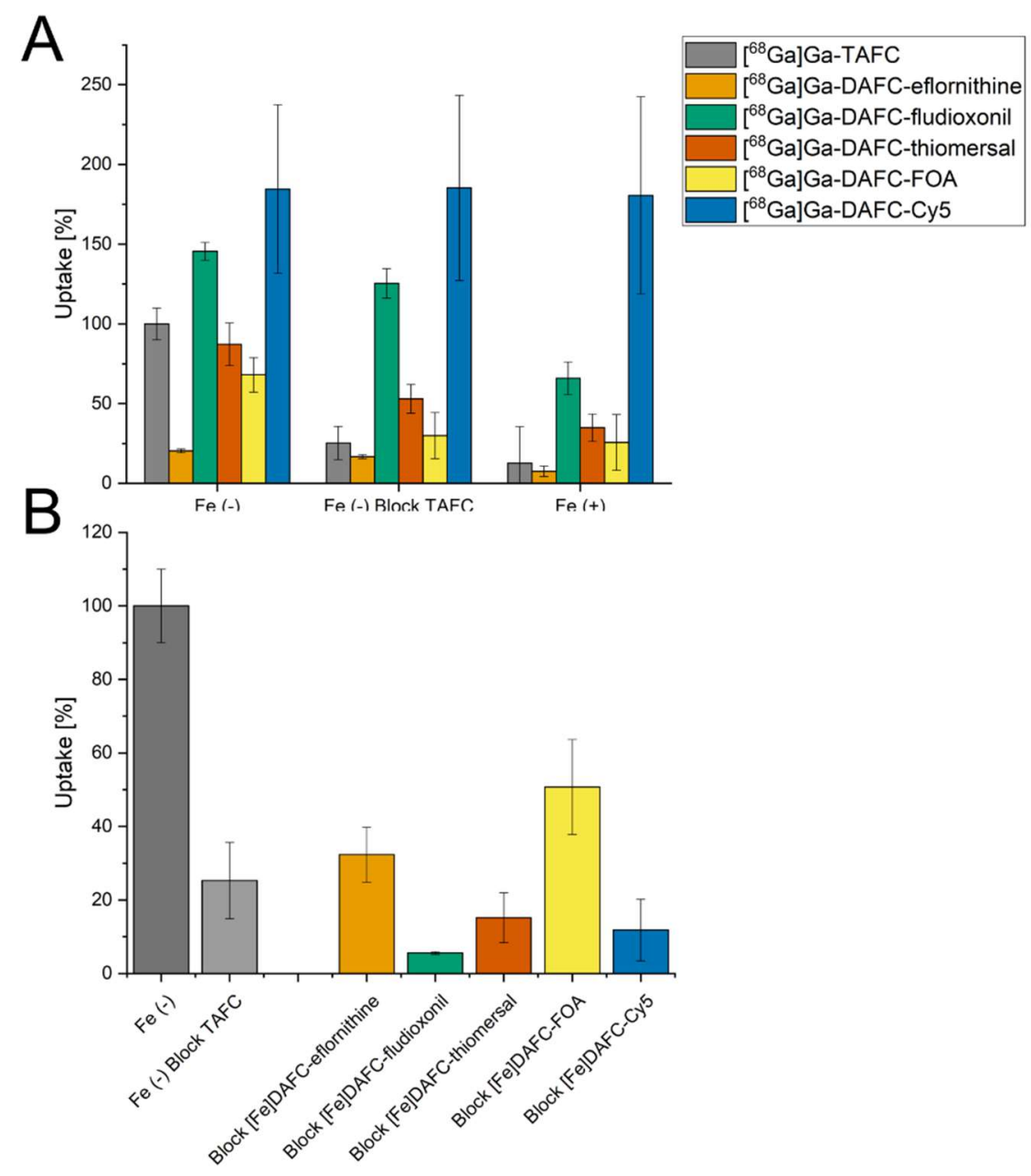

Figure 2. (A) Uptake of radiolabelled antifungal conjugates normalized to reference uptake of $\left[{ }^{68} \mathrm{Ga}\right] \mathrm{Ga}-\mathrm{TAFC}$ of each experiment, respectively. Grey bars represent control with $\left[{ }^{68} \mathrm{Ga}\right] \mathrm{Ga}-\mathrm{TAFC}$. Blocking experiments with $[\mathrm{Fe}] \mathrm{TAFC}$ due to competition at the MirB transporter should reduce uptake. Iron-replete conditions $[\mathrm{Fe}(+)]$ lead to a downregulation of MirB biosynthesis and active uptake of siderophores into the hyphae. (B) Competition assay of $\left[{ }^{68} \mathrm{Ga}\right] \mathrm{Ga}$-TAFC blocked with iron-containing antifungal conjugates in iron-depleted fungal culture. For all compounds a reduction of $\left[{ }^{68} \mathrm{Ga}\right] \mathrm{Ga}-\mathrm{TAFC}$ uptake could be observed, indicating a specific interaction with the MirB transporter. Data of DAFC-Cy5 adopted from reference [18].

\section{Growth promotion assay}

Growth promotion of the mutant strain of $A$. fumigatus $(\triangle \operatorname{sid} A / \Delta f t r A)$ by [Fe]DAFC-conjugates is shown in Figure 3. Control with [Fe]TAFC showed a growth induction at $0.1 \mu \mathrm{M}$ and sporulation at 10 $\mu \mathrm{M}$, seen by the green colored conidia of $A$. fumigatus. Similar growth as in [Fe]TAFC containing media could be observed for [Fe]DAFC-eflornithine, -fludioxonil and -FOA, whereby with eflornithine and FOA conjugates sporulation was shown at $50 \mu \mathrm{M}$. Both, [Fe]DAFC-thiomersal and -Cy5 showed no growth promotion at all, indicating that iron from these conjugates cannot be utilized. It should also be considered that there is a competition between iron induced growth and a growth inhibitory effect of $\mathrm{Cy} 5$, but the positive impact of iron is only present if the fungus can utilize iron from the siderophore. This limitation should be kept in mind. 


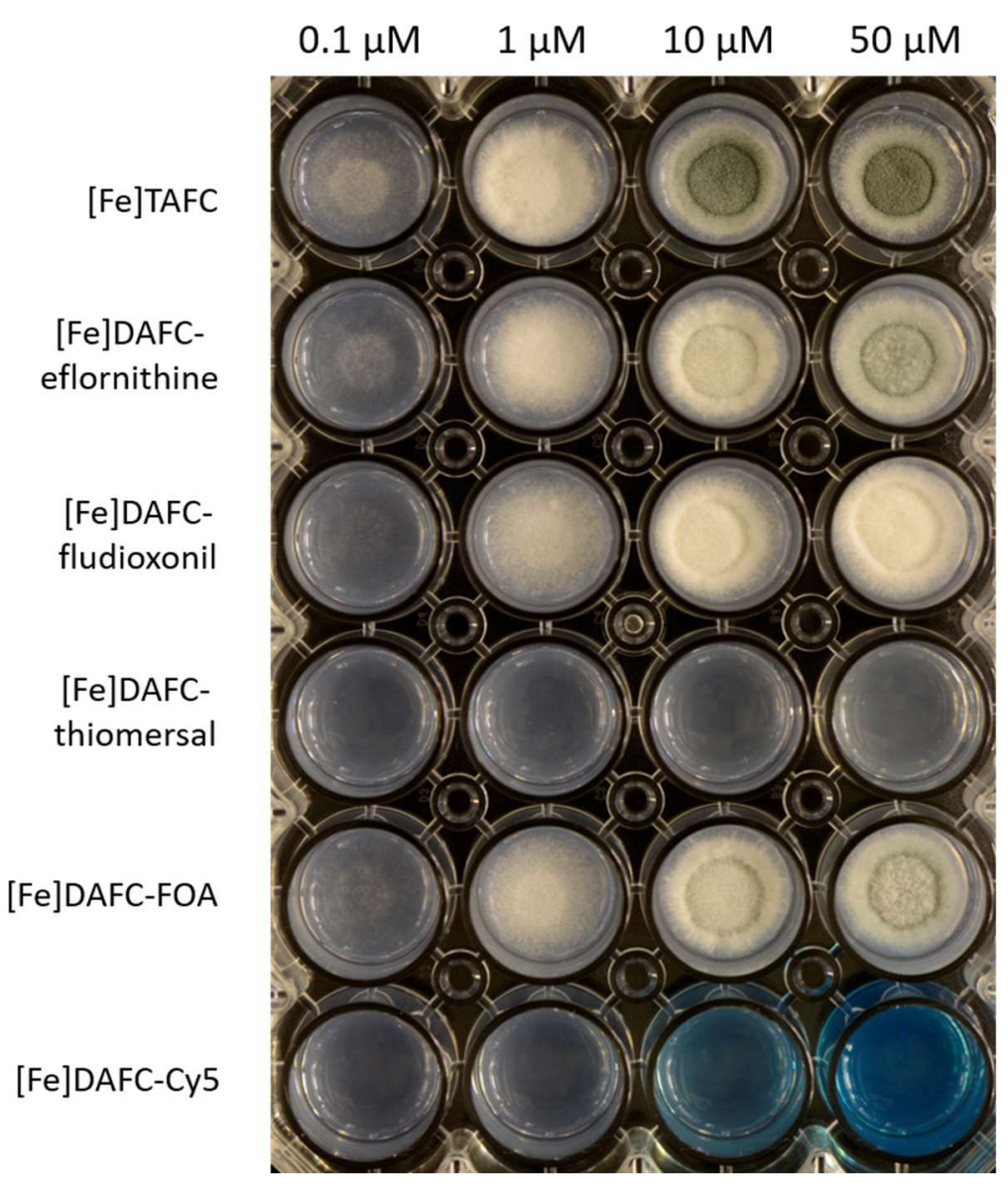

Figure 3. Growth promotion of $A$. fumigatus mutant strain $\Delta$ sidA/ $\Delta$ ftrA after $48 \mathrm{~h}$ incubation at $37^{\circ} \mathrm{C}$ on iron depleted $\mathrm{AMM}$ with different concentrations of iron labelled conjugates. Hyphal growth can be distinguished from greenish (sporulation) and whitish (sterile) mycelia.

\section{Antifungal susceptibility assays}

Antifungal susceptibility assays were performed to evaluate the antifungal potential of the newly synthesized conjugates. Assays were performed as described in the method section, with defining the MIC as the lowest concentration resulting in no visible growth seen by the naked eye. A graphic overview is shown in Figure 4 and a list of all data is included in the supplementary material (Table S1). Most iron containing compounds showed a higher MIC value compared to their gallium labelled counterparts, except for DAFC-eflornithine and -thiomersal, which can be explained by the growth promoting effect of iron during iron starvation. Since gallium has an antifungal effect by itself [38], [Ga]TAFC is shown as a control but growth inhibition did not persist up to $48 \mathrm{~h}$. Thiomersal conjugates showed the strongest growth inhibition but there was no difference to iron-sufficient media (MirB suppression) or to the original molecule, indicating that antifungal activity is not depending on active uptake by the fungus. [Ga]DAFC-fludioxonil, -FOA and -Cy5 showed promising MIC values, that were higher in iron-sufficient media (indicating MirB dependence) and lower than the original molecule (enhanced antifungal effect due to active uptake) except for fludioxonil. Chemical modification of the original molecule fludioxonil $(0.5 \mu \mathrm{g} / \mathrm{mL})$ reduced antifungal effect (fludioxonil butyric acid: $32 \mu \mathrm{g} / \mathrm{mL}$ see Table S1) but MIC value of the modified molecule was still preserved after conjugation. Eflornithine revealed no antifungal effect according to the definition of no visual growth, but still a growth reducing effect was observed. Microscopic pictures of all MIC results at $24 \mathrm{~h}$ can be seen in the supplementary material. (Figure S3 and S4) 


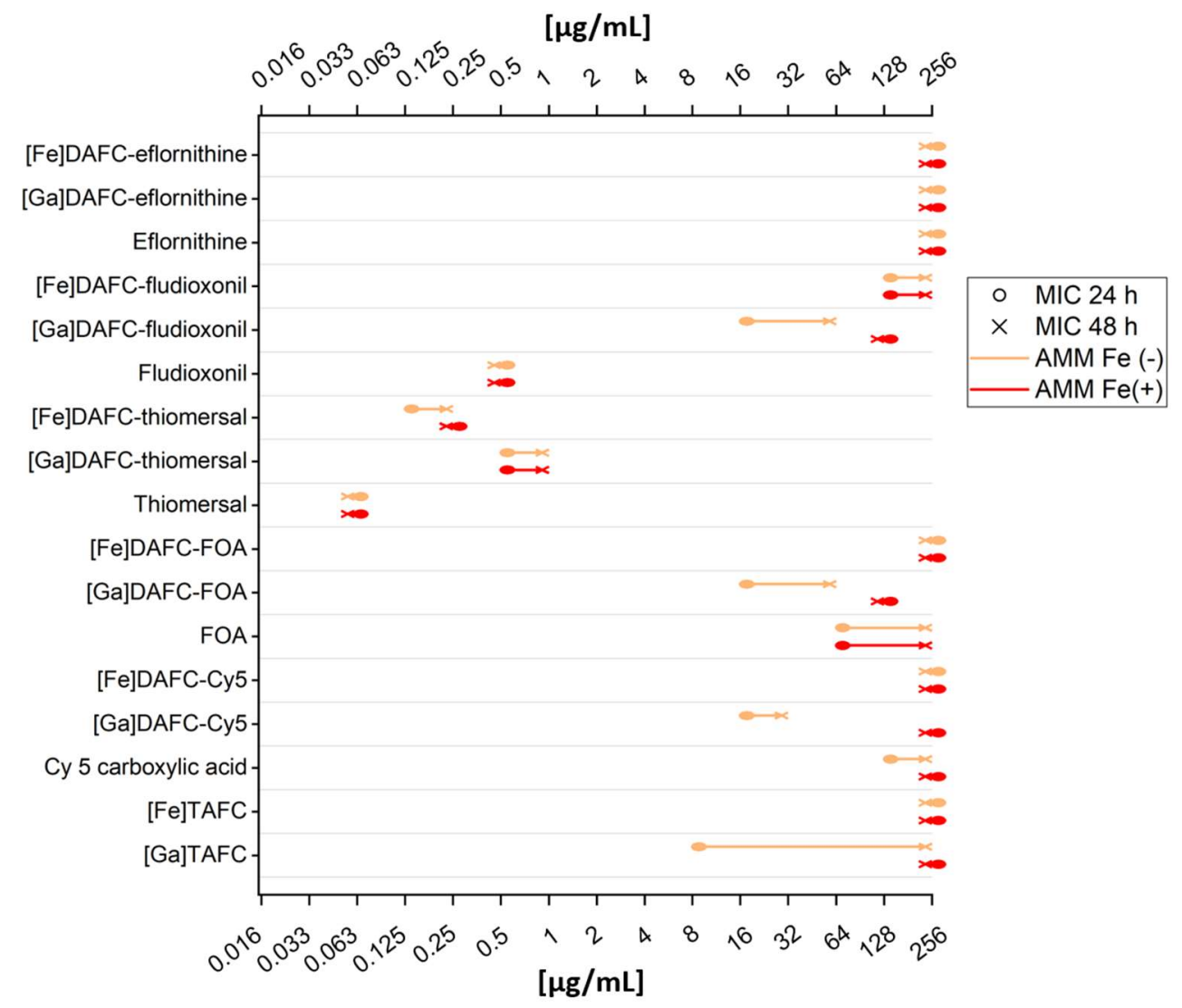

Figure 4. Scheme of all MIC results presented in this study. Orange lines present MIC values with iron-depleted medium (overexpression of the MirB transporter). Red lines are with ironsufficient medium, which downregulates uptake by siderophore transporters such as MirB. Circle dot of the line displays $24 \mathrm{~h}$ and the " $\mathrm{x}$ " dot $48 \mathrm{~h}$. Table with all data points is included in the supplementary material (Table S1).

\section{In vivo Experiments}

\section{In vivo Stability and Biodistribution}

Results of in vivo stability of the different compounds were very heterogeneous and shown in Table 2. $\left[{ }^{68} \mathrm{Ga}\right] \mathrm{Ga}-\mathrm{DAFC}$-eflornithine and -FOA showed a very high stability both in blood and urine samples. $\left[{ }^{68} \mathrm{Ga}\right] \mathrm{Ga}-\mathrm{DAFC}-\mathrm{Cy} 5$ showed no degradation in the blood but there was almost no intact conjugate after excretion through the urinary tract. The last two compounds $\left[{ }^{68} \mathrm{Ga}\right] \mathrm{Ga}-\mathrm{DAFC}$-fludioxonil and thiomersal revealed a high instability in both tested compartments. Only for thiomersal-conjugate instability was also be observed in the in vitro serum stability tests.

Biodistribution after $45 \mathrm{~min}$ and $90 \mathrm{~min}$ of antifungal conjugates are shown in Table 3 . The main excretion of $\left[{ }^{68} \mathrm{Ga}\right] \mathrm{Ga}$-DAFC-eflornithine seemed to be the urinary tract with retention in the kidneys of around $20 \%$, comparable to its high hydrophilicity and stability. On the contrary, $\left[{ }^{68} \mathrm{Ga}\right] \mathrm{Ga}$-DAFCfludioxonil showed an accumulation on the intestine of the mouse and therefore indicated hepatobiliary excretion. Very high blood levels were found for $\left[{ }^{68} \mathrm{Ga}\right] \mathrm{Ga}$-DAFC-thiomersal, which correlated with the protein binding values found in vitro. Accumulation in the intestine and kidney retention was also found for this compound. Similar to these results $\left[{ }^{68} \mathrm{Ga}\right] \mathrm{Ga}$-DAFC-Cy5 showed overall higher blood levels but also an increasing accumulation of compound in the intestine $(15-24 \%$; $45-90 \mathrm{~min})$ as well as in the kidneys (20-23\%). This could be a limitation for PET imaging due to higher background signal. $\left[{ }^{68} \mathrm{Ga}\right] \mathrm{Ga}-\mathrm{DAFC}-\mathrm{FOA}$ showed no significant accumulation in any organ over time. 
bioRxiv preprint doi: https://doi.org/10.1101/2021.04.19.440472; this version posted April 19, 2021. The copyright holder for this preprint (which was not certified by peer review) is the author/funder, who has granted bioRxiv a license to display the preprint in perpetuity. It is made available under aCC-BY-NC-ND 4.0 International license.

Table 2. In vivo stability of different antifungal conjugates radiolabelled with gallium-68. Samples form BALB/c mice 10 min after injection into the tail vain. Values reflect intact conjugate measured by radio-HPLC analysis. (Each value represents two biological replicates)

\begin{tabular}{cccccc}
\hline & $\begin{array}{c}{\left[{ }^{68} \mathrm{Ga}\right] \mathrm{Ga}-\mathrm{DAFC}-} \\
\text { eflornithine }\end{array}$ & $\begin{array}{c}{\left[{ }^{68} \mathrm{Ga}\right] \mathrm{Ga}-\mathrm{DAFC}-} \\
\text { fludioxonil }\end{array}$ & $\begin{array}{c}{\left[{ }^{68} \mathrm{Ga}\right] \mathrm{Ga}-\mathrm{DAFC}-} \\
\text { thiomersal }\end{array}$ & $\begin{array}{c}{\left[{ }^{68} \mathrm{Ga}\right] \mathrm{Ga}-\mathrm{DAFC}-} \\
\text { FOA }\end{array}$ & $\begin{array}{c}{\left[{ }^{68} \mathrm{Ga}\right] \mathrm{Ga}-\mathrm{DAFC}-} \\
\text { Cy5 }\end{array}$ \\
\hline Blood & $98.0 \%$ & $40.6 \%$ & $26.7 \%$ & $>99.0 \%$ & $>99.0 \%$ \\
Urine & $99.0 \%$ & $9.8 \%$ & $30.5 \%$ & $>99.0 \%$ & $5.2 \%$ \\
\hline
\end{tabular}


Table 3. Biodistribution of gallium- 68 labelled antifungal compounds in standard BALB/c mice. Injected into the tail vein and measured after 45 and 90 min, shown as injected dose per gram tissue $(\% \mathrm{ID} / \mathrm{g})$. Important values are highlighted in bold. (Each value represents three biological replicates)

\begin{tabular}{|c|c|c|c|c|c|c|c|c|c|c|}
\hline \multirow[t]{2}{*}{ Organ } & \multicolumn{2}{|c|}{$\begin{array}{c}{\left[{ }^{68} \mathrm{Ga}\right] \mathrm{Ga}-\mathrm{DAFC}-} \\
\text { eflornithine }\end{array}$} & \multicolumn{2}{|c|}{$\begin{array}{c}{\left[{ }^{68} \mathrm{Ga}\right] \mathrm{Ga}-\mathrm{DAFC}-} \\
\text { fludioxonil }\end{array}$} & \multicolumn{2}{|c|}{$\left[{ }^{68} \mathrm{Ga}\right] \mathrm{Ga}-\mathrm{DAFC}$-thiomersal } & \multicolumn{2}{|c|}{$\left[{ }^{68} \mathrm{Ga}\right] \mathrm{Ga}-\mathrm{DAFC}-\mathrm{FOA}$} & \multicolumn{2}{|c|}{$\left[{ }^{68} \mathrm{Ga}\right] \mathrm{Ga}-\mathrm{DAFC}-\mathrm{Cy} 5$} \\
\hline & $45 \mathrm{~min}$ & $90 \mathrm{~min}$ & $45 \mathrm{~min}$ & $90 \mathrm{~min}$ & $45 \mathrm{~min}$ & $90 \mathrm{~min}$ & $45 \mathrm{~min}$ & $90 \mathrm{~min}$ & $45 \mathrm{~min}$ & $90 \mathrm{~min}$ \\
\hline Blood & $0.93 \pm 0.63$ & $0.13 \pm 0.03$ & $0.17 \pm 0.06$ & $0.14 \pm 0.02$ & $10.35 \pm 3.35$ & $3.21 \pm 0.94$ & $1.30 \pm 0.62$ & $0.13 \pm 0.04$ & $4.38 \pm 1.02$ & $3.37 \pm 0.65$ \\
\hline Spleen & $0.38 \pm 0.05$ & $0.22 \pm 0.01$ & $0.32 \pm 0.06$ & $0.30 \pm 0.05$ & $1.82 \pm 0.64$ & $0.61 \pm 0.12$ & $0.33 \pm 0.08$ & $0.12 \pm 0.04$ & $1.56 \pm 0.15$ & $5.58 \pm 0.94$ \\
\hline Pancreas & $0.31 \pm 0.07$ & $0.06 \pm 0.01$ & $0.05 \pm 0.01$ & $0.04 \pm 0.00$ & $1.59 \pm 0.61$ & $0.45 \pm 0.09$ & $0.28 \pm 0.04$ & $0.06 \pm 0.02$ & $0.56 \pm 0.07$ & $0.46 \pm 0.12$ \\
\hline Stomach & $0.28 \pm 0.06$ & $0.09 \pm 0.03$ & $0.94 \pm 1.12$ & $0.25 \pm 0.22$ & $1.77 \pm 0.50$ & $0.72 \pm 0.24$ & $0.40 \pm 0.07$ & $0.13 \pm 0.07$ & $3.95 \pm 3.13$ & $1.77 \pm 1.61$ \\
\hline Intestine & $0.68 \pm 0.08$ & $0.51 \pm 0.05$ & $23.08 \pm 2.43$ & $25.19 \pm 1.18$ & $19.41 \pm 7.26$ & $13.63 \pm 1.37$ & $2.68 \pm 0.54$ & $2.52 \pm 0.40$ & $15.82 \pm 0.31$ & $24.73 \pm 0.34$ \\
\hline Kidneys & $23.01 \pm 2.23$ & $19.35 \pm 4.55$ & $0.22 \pm 0.03$ & $0.20 \pm 0.03$ & $7.43 \pm 2.24$ & $3.67 \pm 0.98$ & $2.72 \pm 0.21$ & $1.75 \pm 0.21$ & $4.60 \pm 0.52$ & $3.37 \pm 0.68$ \\
\hline Liver & $0.55 \pm 0.03$ & $0.38 \pm 0.05$ & $2.20 \pm 0.49$ & $0.83 \pm 0.23$ & $3.67 \pm 0.38$ & $2.37 \pm 0.83$ & $0.70 \pm 0.34$ & $0.60 \pm 0.38$ & $19.73 \pm 2.25$ & $22.95 \pm 1.57$ \\
\hline Heart & $0.28 \pm 0.07$ & $0.07 \pm 0.01$ & $0.07 \pm 0.02$ & $0.06 \pm 0.02$ & $3.03 \pm 0.91$ & $0.97 \pm 0.14$ & $0.33 \pm 0.09$ & $0.07 \pm 0.00$ & $1.39 \pm 0.11$ & $1.25 \pm 0.25$ \\
\hline Lung & $0.89 \pm 0.16$ & $0.24 \pm 0.04$ & $0.32 \pm 0.26$ & $0.18 \pm 0.09$ & $7.04 \pm 2.67$ & $2.96 \pm 1.75$ & $0.66 \pm 0.02$ & $0.21 \pm 0.06$ & $2.95 \pm 0.20$ & $1.95 \pm 0.25$ \\
\hline Muscle & $0.33 \pm 0.23$ & $0.04 \pm 0.01$ & $0.04 \pm 0.01$ & $0.03 \pm 0.01$ & $1.25 \pm 0.49$ & $0.36 \pm 0.10$ & $0.20 \pm 0.02$ & $0.05 \pm 0.02$ & $0.50 \pm 0.12$ & $0.45 \pm 0.11$ \\
\hline Femur & $0.21 \pm 0.09$ & $0.11 \pm 0.04$ & $0.07 \pm 0.02$ & $0.09 \pm 0.06$ & $1.50 \pm 0.72$ & $0.56 \pm 0.22$ & $0.45 \pm 0.17$ & $0.14 \pm 0.03$ & $0.80 \pm 0.43$ & $0.85 \pm 0.13$ \\
\hline
\end{tabular}

Data are presented as mean $\pm \mathrm{SD}$. 
bioRxiv preprint doi: https://doi.org/10.1101/2021.04.19.440472; this version posted April 19, 2021. The copyright holder for this preprint (which was not certified by peer review) is the author/funder, who has granted bioRxiv a license to display the preprint in perpetuity. It is made available under aCC-BY-NC-ND 4.0 International license.

\section{PET/CT images}

In Figure 5 coronal PET/CT slices of non-infected Lewis-rats are shown, injected with different ${ }^{68}$ Ga-labelled antifungal siderophore conjugates. $\left[{ }^{68} \mathrm{Ga}\right] \mathrm{Ga}-\mathrm{DAFC}$-eflornithine and -FOA showed a primary excretion through the urinary tract with clear delineation of the kidneys and bladder. As already described in the biodistribution experiments, $\left[{ }^{68} \mathrm{Ga}\right] \mathrm{Ga}-\mathrm{DAFC}-\mathrm{fludioxonil}$, -thiomersal and -Cy5 were excreted through the hepatobiliary way which resulted in a high signal in the intestinal region.

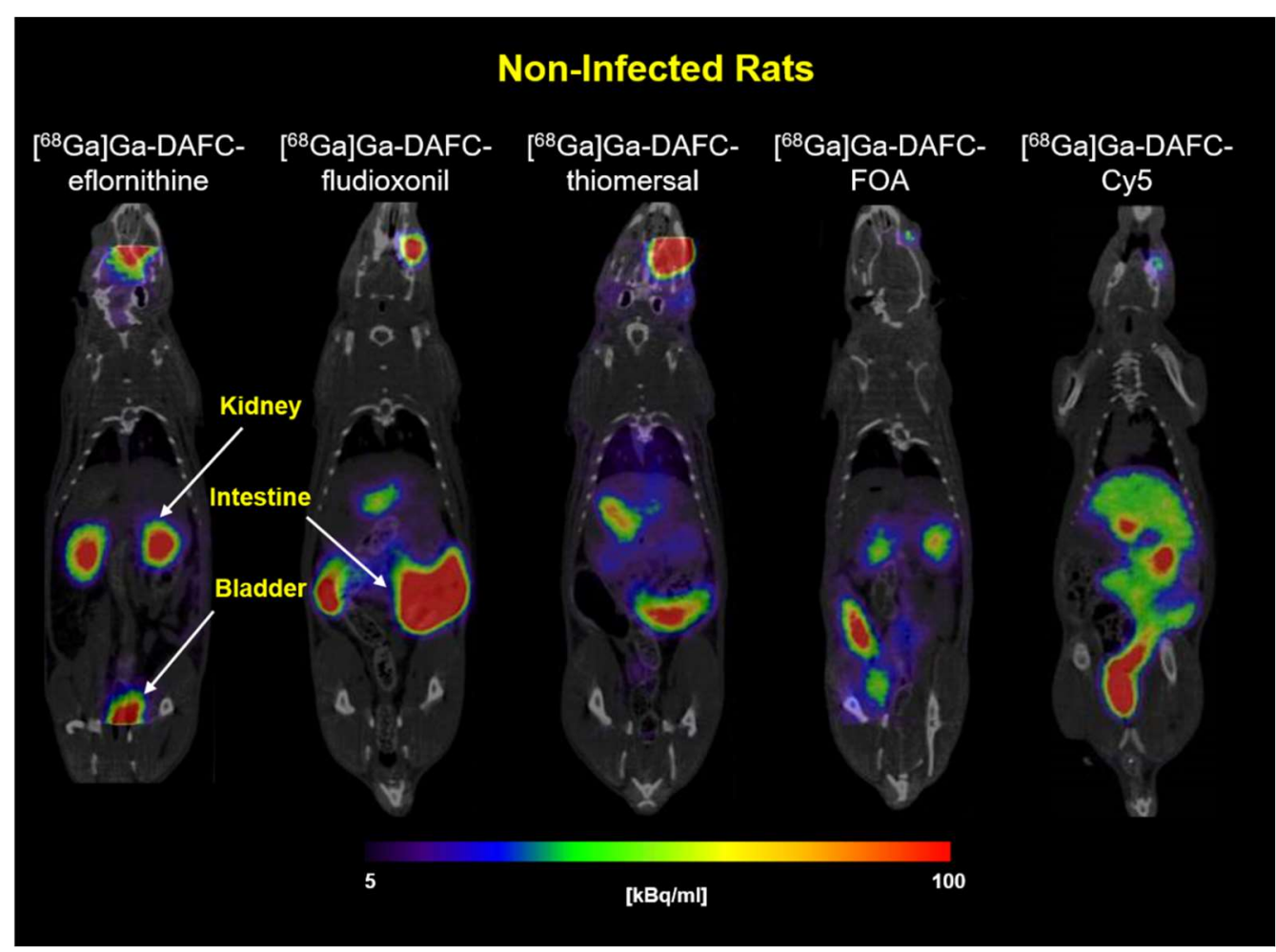

Figure 5. Coronal PET/CT of non-infected Lewis-rats after $45 \mathrm{~min}$ post injection of $68 \mathrm{Ga}-$ labelled siderophore conjugates (approx. 5-10 MBq injected dose). Kidneys, intestine and bladder are highlighted by arrows in the picture. Radioactive spots in the eye region originate from the retro-orbital injection.

PET/CT images of Lewis-rats infected with A. fumigatus in the lung, displayed an accumulation of all antifungal conjugates in the infected region. (Figure 6) CT images of the lung revealed anatomical changes with co-localization of radioactive signal. Skriba et al. showed that these anatomical changes originate from infection with A. fumigatus which was also confirmed by histological examination [36]. Compared to non-infected animals, no significant radioactive signal could be observed in the lung region for all siderophore conjugates. 


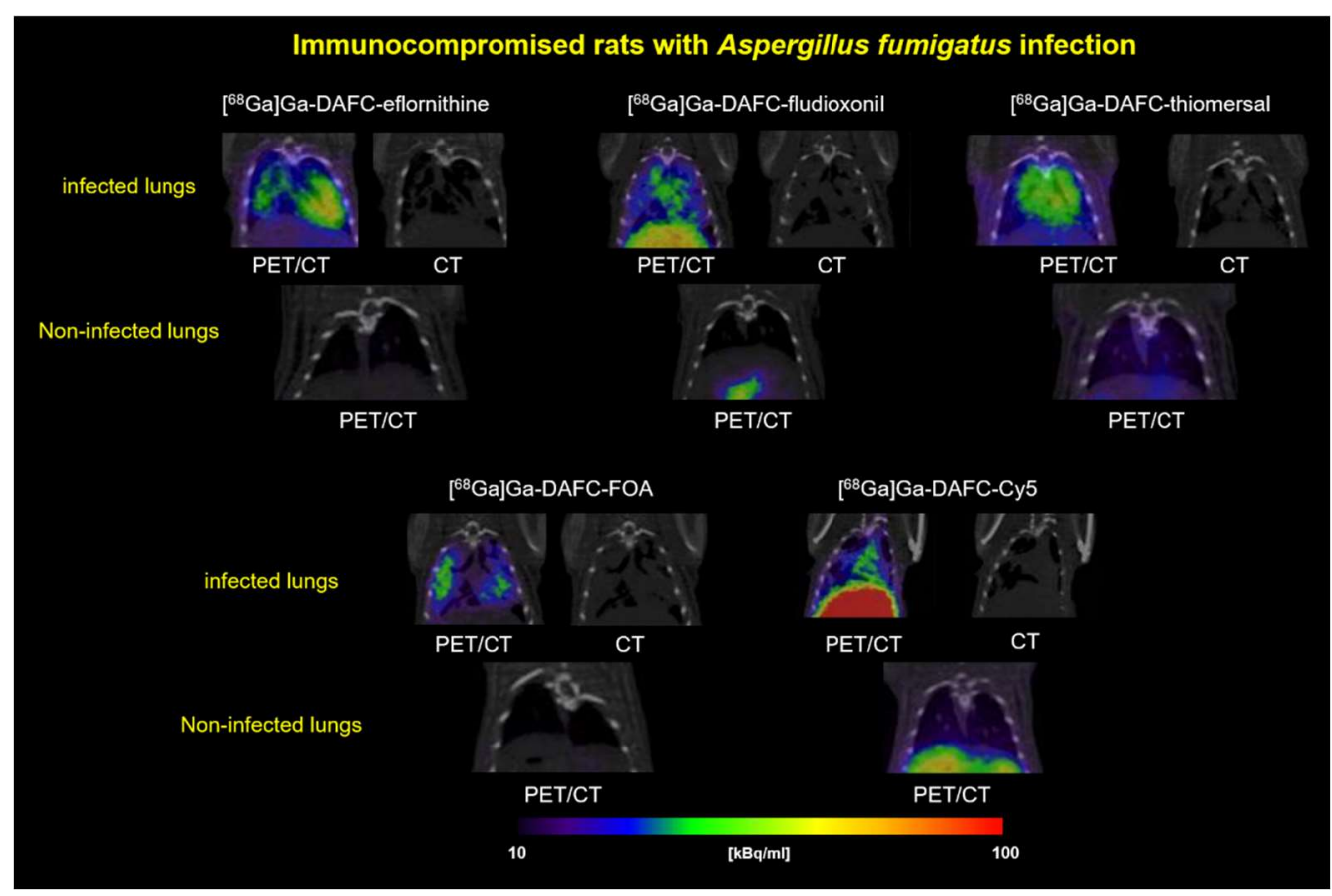

Figure 6. Coronal PET/CT slices of immunocompromised Lewis-rats infected with A. fumigatus in the lung. Pictures are showing the lung section of infected (top row) and non-infected (bottom row, control) rats of each compound respectively. Animals were injected retro-orbitally and pictures made after 45 min with approx. 5-12 MBq injected dose. CT images were added to show the severity of the infected lung tissue.

\section{Discussion}

Antimicrobial siderophores have been attracting the interest of scientists for many decades. First discovered as natural products of bacteria, so called sideromycins, they were investigated as antibacterial compounds e.g. salmycin and albomycin for growth inhibition of Streptococcus pneumoniae and Staphylococcus aureus $[39,40]$. This natural concept of utilizing the iron acquisition system of bacteria to channel antibacterial molecules inspired the development of new synthetic compounds. For example, pyoverdine (siderophore) conjugated with ampicillin (beta-lactam antibiotic) against Pseudomonas aeruginosa [41]. The big advantage of the synthetic strategy is the high variability of conjugation partners. It is possible to use these siderophores as a "Trojan horse" to smuggle all kinds of molecules into bacteria [42]. The recently approved drug Cefiderocol (Fetroja $\left.{ }^{\circledR}\right)$ by the FDA (Nov 2019) is the first artificial sideromycin on the market consisting of a catechol chelating unit and a cephalosporin antibiotic (beta-lactam) against gram-negative bacteria [43].

This Trojan horse concept can be adopted for fungal species as well, using fungal specific siderophores to deliver antifungal molecules. Previous research published by our group showed that fluorescence dyes could be attached to [Fe]DAFC and a specific fluorescence signal could be detected in A. fumigatus hyphae that was dependent on active uptake via MirB [18]. Furthermore, "large" antifungal peptides were attached to [Fe]DAFC to inhibit fungal growth but unfortunately no antifungal effect could be observed [34]. In this study we attempted to modify TAFC with small organic molecules that have known antifungal properties described in the literature and label them with gallium- 68 to perform PET/CT images of $A$. fumigatus lung infections in a rat model.

Synthesis of the conjugates was straight forward, with high purity of the resulting compounds. Modifications had to be made for eflornithine, to provide better synthetic yields with a lower rate of side products. Fludioxonil had to be chemically modified by adding a linker function to its molecular structure for coupling to DAFC. The new compounds were labelled with gallium- 68 to perform in vitro and in vivo tests. Labelling resulted in a high radiochemical purity under mild conditions (10 min, room temperature, $\mathrm{pH}=4.5$ ). 
Siderophore conjugates used within this research were produced in two different modifications: iron-containing ([Fe]DAFC) and gallium-labelled ([Ga]DAFC) conjugates. The rationale behind using gallium instead of iron was to enhance targeting efficiency because the iron transported by siderophores leads in A. fumigatus after uptake to downregulation of siderophore transporters such as MirB [44]. This would lead to a reduction or even cessation of siderophore uptake into the hyphae and in the case of antifungal conjugates, resulting in a better survival of the fungus. Additionally, iron as an essential nutrient has a growth-enhancing effect on fungi. Gallium nitrate is a FDA approved drug, used in cancerrelated hypercalcemia $\left(\right.$ Ganite $^{\circledR}$ ) and showed a very good tolerance in patients [45]. It should be considered, that gallium itself has an antifungal effect on microorganisms [46]. Bastos et al. have shown that $\mathrm{Ga}\left(\mathrm{NO}_{3}\right)_{3}$ has an antifungal effect on A. fumigatus cultures in different media [38] and $\mathrm{Ga}\left(\mathrm{NO}_{3}\right)_{3}$ is also currently investigated against Pseudomonas aeruginosa lung infection of adults with cystic fibrosis in a clinical trial [47]. So far, it is not completely clear how gallium influences the antifungal activity of the described siderophore conjugates but MIC tests with [Ga]TAFC showed an inhibition of growth at $8 \mu \mathrm{g} / \mathrm{mL}$ and $24 \mathrm{~h}$ but after $48 \mathrm{~h}$ no inhibition was observed anymore. Fungistatic behavior of $\mathrm{Ga}\left(\mathrm{NO}_{3}\right)_{3}$ have also been described by Bastos et al. in AMM [38]. As seen in Figure 4, an overall better fungal growth inhibition was observed for gallium labelled conjugates in comparison to iron labelled counterparts. In the development of antimicrobial siderophore conjugates as "Trojan horse", Miller, Nolan, and others, who generated fundamental knowledge in antibiotic conjugates, always used iron for labelling of their compounds [48-51]. One of the first reports on enhancing antibacterial potency by labelling with gallium was published by Pandey et al. with Ferrichrome-Ciprofloxacin against Escherichia coli. They observed a 2-4 fold enhancement of activity compared to the iron complex [52].

Antifungal susceptibility assays revealed the potential of fungal growth inhibition by the produced antifungal siderophore conjugates. To test their MirB transporter dependency, two different media were used: iron depleted AMM Fe(-) (upregulation of MirB transporter,) and iron sufficient media AMM $\mathrm{Fe}(+)$ (control, no active transport). Except for [Ga]DAFC-eflornithine and -thiomersal, all galliumlabelled compounds showed a MirB dependent antifungal effect. Thiomersal conjugates, revealed an overall low MIC value independent on the media and labelling with gallium or iron, which is probably due to cleavage outside the hyphae resulting in ethylmercury (active metabolite) causing growth inhibition. Higher instability in human serum and in vivo fortifies these assumption but this limits the applicability, because adverse health effects of ethylmercury are still controversially discussed [31]. [Ga]DAFC-fludioxonil $(16 \mu \mathrm{g} / \mathrm{mL})$, -FOA $(16 \mu \mathrm{g} / \mathrm{mL})$ and Cy5 $(16 \mu \mathrm{g} / \mathrm{mL})$ showed a growth reduction of 3 to 4 dilution steps in iron depleted media compared to iron sufficient after $24 \mathrm{~h}$ giving a proof of principle for a MirB dependent antifungal effect. eflornithine revealed no antifungal effect independent of the siderophore conjugation.

Competition assay with iron-containing antifungal conjugates blocking uptake of $\left[{ }^{68} \mathrm{Ga}\right] \mathrm{Ga}-\mathrm{TAFC}$ showed a specific interaction of all conjugates with the MirB transporter encouraging the hypothesis of a transporter dependent effect. Uptake assays of $\left[{ }^{68} \mathrm{Ga}\right] \mathrm{Ga}$-DAFC-fludioxonil, -thiomersal, -FOA and Cy5 showed a high accumulation by A. fumigatus hyphae, however, uptake of Cy5 could not be blocked by $[\mathrm{Fe}] \mathrm{TAFC}$ or iron sufficient media. This unspecific binding was already observed in earlier studies and origins probably due to interaction with the outer cell compartment $[18,19]$. Uptake of $\left[{ }^{68} \mathrm{Ga}\right] \mathrm{Ga}-$ DAFC-eflornithine was notably low, which could be one reason, why no antifungal effect was observed when coupled to [Ga]DAFC. Growth assays confirmed utilization of DAFC-eflornithine, -fludioxonil, and FOA, whereas [Fe]DAFC-Cy5 and -thiomersal did not promote growth, providing limited additional information towards the theranostic properties of these compounds.

Beside growth inhibiting properties, pharmacokinetics of these novel antifungal siderophore conjugates should be especially considered, which could predict diagnostic and clinical properties. [53] PET/CT images of non-infected rats show the distribution of radioactive labelled compound and main excretion routes supported by biodistribution results. $\left[{ }^{68} \mathrm{Ga}\right] \mathrm{Ga}$-DAFC-eflornithine and FOA were manly excreted through the kidney and bladder of the rats. These findings are in line with a low protein binding capacity and a hydrophilic character of the compounds. In a diagnostic setting, a rapid elimination from the body lowers radiation burden for the patient and allows high image resolution. Lipophilic compounds like $\left[{ }^{68} \mathrm{Ga}\right] \mathrm{Ga}$-DAFC-fludioxonil, -thiomersal and -Cy5 are manly excreted through liver and intestine as seen in PET/CT images and in biodistribution studies. This would lead to 
a higher background signal, which would be less of a problem since IPA infections are located in the lungs, but it would lead to a higher radiation burden to the patient. Increased blood levels of $\left[{ }^{68} \mathrm{Ga}\right] \mathrm{Ga}$ DAFC-thiomersal and -Cy5 would be also not beneficial from a diagnostic prospective, however, a therapeutic effect could be enhanced due to longer circulation times. Studies from the recently approved drug Cefiderocol $\left(\right.$ Fetroja $^{\circledR}$ ) against gram-negative bacteria revealed an in vitro plasma binding of $58 \%$ and a main clearance through the kidneys (>90\%) [54]. A longer circulation time of antifungal siderophore compound could increase the likelihood of uptake by the fungus resulting in a better therapeutic outcome.

Diagnostic applicability of these compounds was tested in an A. fumigatus lung infection in a rat model. All conjugates revealed uptake into the infected area of the lung and a visualization in PET/CT. This specific accumulation holds promise for a therapeutic effect in vivo. Images were similar to previous infections images with $\left[{ }^{68} \mathrm{Ga}\right] \mathrm{Ga}-\mathrm{TAFC}$ by Petrik et al. $[55]$ and modified $\left[{ }^{68} \mathrm{Ga}\right] \mathrm{Ga}-\mathrm{TAFC}$ by Kaeopookum et al. [17]. PET/MRI pictures by Henneberg et al. using the Aspergillus specific antibody hJF5 labelled with copper-64 to visualize an A. fumigatus infection, showed also similar patterns in a mouse model [56].

Taken together, antifungal siderophore conjugates synthesized within this study are highly interesting model compounds for theranostic applications in fungal infections. The concept of using siderophore conjugates for theranostics, combining gallium-68 for PET with a therapeutic moiety have first been described by Ferreira et al [57]. They coupled siderophore catecholate binding moieties to a DOTAM scaffold, and additionally ampicillin for antibacterial activity. The iron containing compound did not reveal antibacterial activity in wild type E.coli, but specific in vitro uptake could be proven. In vivo data of the therapeutic conjugate have not been provided. More recently Pandey et al. [52] reported a siderophore ciprofloxacin conjugate based on ferrichrome. They showed a siderophore iron transportdependent internalization of one compound and antibacterial activity against Peudomonas aeruginosa, Staphylococcus aureus and Klebsiella pneumoniae of the Gallium (III) complex, whereas the Ferric complexes remained inactive, similar to our findings. They also reported biodistribution data in normal mice, but no data in animal infection models. Both studies also failed to provide proof of a therapeutic effect in respective infection models. Our study overall confirmed these findings for theranostics in fungal disease, which so far have not been described. Additionally we provided for the first time, specific in vivo targeting of infections with such "Trojan horse" conjugates by PET imaging and could show that the antifungal efficacy in most compounds was clearly related to the siderophore transport target MirB. Data obtained in this study give highly valuable information for synthesis of future compounds with higher antifungal potency which bear great potential for diagnostic and therapeutic use.

\section{Conclusions}

In this study, we successfully modified TAFC with a variety of antifungal molecules with divergent mechanism of action, unrelated to commonly used therapeutics. Targeting the iron acquisition system of $A$. fumigatus with these antifungal siderophore conjugates revealed a proof of principle to utilize MirB for delivering a variety of antifungals, to inhibit fungal growth in antifungal susceptibility tests. By labelling the compounds with gallium-68, a lung infection of A. fumigatus in a rat model was confirmed, also revealing insights about the influence of the conjugation partners on pharmacokinetic properties. Knowledge gained within this research could lead to sophisticated strategies in the field of IPA infections, combining imaging and therapy in a theranostic approach.

Funding: This research was funded by the Austrian Science Fund (FWF): project number P 30924B26 to CD and the Austrian Research Promotion Agency FFG [West Austrian BioNMR858017] by BM. 
bioRxiv preprint doi: https://doi org/10.1101/2021.04 19.440472; this version posted April 19, 2021. The copyright holder for this preprint (which was not certified by peer review) is the author/funder, who has granted bioRxiv a license to display the preprint in perpetuity. It is made available under aCC-BY-NC-ND 4.0 International license.

Conflicts of Interest: The authors declare no conflict of interest

\section{Abbreviation}

A. fumigatus: Aspergillus fumigatus

AMM: Aspergillus minimal medium

ACN: Acetonitrile

DAFC: Diacetylfusarinine C

FsC: Fusarinine $\mathrm{C}$

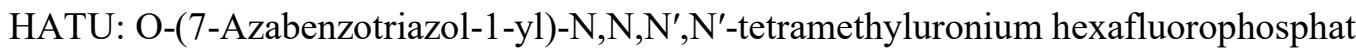

MIC: Minimal inhibitory concentration

$\mathrm{Na}_{2}$ EDTA: Ethylenediaminetetraacetic acid disodium salt

PBS: Phosphate buffer saline

SIT: Siderophore iron tranpsorter

TAFC: Triacetylfusarinine C

TRIS: Tris(hydroxymethyl)aminomethane

PET/CT: Positron Emission Tomography/Computer Tomography

\section{References}

1. Bongomin F, Gago S, Oladele R, Denning D. Global and Multi-National Prevalence of Fungal Diseases_Estimate Precision. J Fungi [Internet]. 2017; 3: 57. Available at:

http://www.mdpi.com/2309-608X/3/4/57

2. Brown GD, Denning DW, Gow NAR, Levitz SM, Netea MG, White TC. Hidden Killers:

Human Fungal Infections. Sci Transl Med [Internet]. 2012; 4: 165rv13-165rv13. Available at: http://stm.sciencemag.org/cgi/doi/10.1126/scitranslmed.3004404

3. Jenks J, Hoenigl M. Treatment of Aspergillosis. J Fungi [Internet]. 2018; 4: 98. Available at: http://www.mdpi.com/2309-608X/4/3/98

4. Latgé J-P. Aspergillus fumigatus and Aspergillosis. Clin Microbiol Rev [Internet]. 1999; 12: 310-50. Available at: https://cmr.asm.org/content/12/2/310

5. Ullmann AJ, Aguado JM, Arikan-Akdagli S, et al. Diagnosis and management of Aspergillus diseases: executive summary of the 2017 ESCMID-ECMM-ERS guideline. Clin Microbiol Infect [Internet]. 2018; 24: e1-38. Available at: https://linkinghub.elsevier.com/retrieve/pii/S1198743X1830051X

6. Moura S, Cerqueira L, Almeida A. Invasive pulmonary aspergillosis: current diagnostic methodologies and a new molecular approach. Eur J Clin Microbiol Infect Dis [Internet]. 2018; 37: 1393-403. Available at: http://link.springer.com/10.1007/s10096-018-3251-5

7. Van Daele R, Spriet I, Wauters J, et al. Antifungal drugs: What brings the future? Med Mycol [Internet]. 2019; 57: S328-43. Available at: https://academic.oup.com/mmy/article/57/Supplement_3/S328/5530955

8. Verweij PE, Lucas JA, Arendrup MC, et al. The one health problem of azole resistance in Aspergillus fumigatus: current insights and future research agenda. Fungal Biol Rev [Internet]. 2020; 34: 202-14. Available at: https://doi.org/10.1016/j.fbr.2020.10.003

9. Nairz M, Weiss G. Iron in infection and immunity. Mol Aspects Med [Internet]. 2020; 75: 100864. Available at: https://doi.org/10.1016/j.mam.2020.100864

10. Haas H. Iron - A Key Nexus in the Virulence of Aspergillus fumigatus. Front Microbiol [Internet]. 2012; 3: 1-10. Available at:

http://journal.frontiersin.org/article/10.3389/fmicb.2012.00028/abstract

11. Schrettl M, Bignell E, Kragl C, et al. Siderophore Biosynthesis But Not Reductive Iron Assimilation Is Essential for Aspergillus fumigatus Virulence. J Exp Med [Internet]. 2004; 200: 1213-9. Available at: http://www.jem.org/lookup/doi/10.1084/jem.20041242

12. Haas H. Fungal siderophore metabolism with a focus on Aspergillus fumigatus. Nat Prod Rep [Internet]. 2014; 31: 1266-76. Available at: http://dx.doi.org/10.1039/C4NP00071D

13. Haas H, Schoeser M, Lesuisse E, et al. Characterization of the Aspergillus nidulans 
bioRxiv preprint doi: https://doi org/10.1101/2021.04.19.440472; this version posted April 19, 2021. The copyright holder for this preprint (which was not certified by peer review) is the author/funder, who has granted bioRxiv a license to display the preprint in perpetuity. It is made available under aCC-BY-NC-ND 4.0 International license.

transporters for the siderophores enterobactin and triacetylfusarinine C. Biochem J [Internet]. 2003; 371: 505-13. Available at: https://portlandpress.com/biochemj/article/371/2/505/40792/Characterization-of-theAspergillus-nidulans

14. Petrik M, Haas H, Laverman P, et al. 68Ga-Triacetylfusarinine $\mathrm{C}$ and $68 \mathrm{Ga}$-Ferrioxamine $\mathrm{E}$ for Aspergillus Infection Imaging: Uptake Specificity in Various Microorganisms. Mol Imaging Biol [Internet]. 2014; 16: 102-8. Available at: http://www.ncbi.nlm.nih.gov/pubmed/23818006

15. Raymond-Bouchard I, Carroll CS, Nesbitt JR, et al. Structural Requirements for the Activity of the MirB Ferrisiderophore Transporter of Aspergillus fumigatus. Eukaryot Cell [Internet]. 2012; 11: 1333-44. Available at: http://ec.asm.org/lookup/doi/10.1128/EC.00159-12

16. Petrik M, Franssen GM, Haas H, et al. Preclinical evaluation of two 68Ga-siderophores as potential radiopharmaceuticals for Aspergillus fumigatus infection imaging. Eur J Nucl Med Mol Imaging [Internet]. 2012; 39: 1175-83. Available at: http://link.springer.com/10.1007/s00259-012-2110-3

17. Kaeopookum P, Summer D, Pfister J, et al. Modifying the Siderophore Triacetylfusarinine C for Molecular Imaging of Fungal Infection. Mol Imaging Biol [Internet]. 2019; 21: 1097-106. Available at: http://link.springer.com/10.1007/s11307-019-01325-6

18. Pfister J, Lichius A, Summer D, et al. Live-cell imaging with Aspergillus fumigatus-specific fluorescent siderophore conjugates. Sci Rep [Internet]. 2020; 10: 15519. Available at: https://doi.org/10.1038/s41598-020-72452-2

19. Pfister J, Summer D, Petrik M, et al. Hybrid Imaging of Aspergillus fumigatus Pulmonary Infection with Fluorescent, 68Ga-Labelled Siderophores. Biomolecules [Internet]. 2020; 10: 168. Available at: https://www.mdpi.com/2218-273X/10/2/168

20. Cardenas ME, Cruz MC, Del Poeta M, Chung N, Perfect JR, Heitman J. Antifungal Activities of Antineoplastic Agents:Saccharomyces cerevisiae as a Model System To Study Drug Action. Clin Microbiol Rev [Internet]. 1999; 12: 583-611. Available at: https://cmr.asm.org/content/12/4/583

21. Carmina E. Topical Eflornithine. Am J Clin Dermatol [Internet]. 2001; 2: 202. Available at: $\mathrm{http}: / /$ link.springer.com/10.2165/00128071-200102030-00011

22. Levin VA, Ictech SE, Hess KR. Clinical importance of eflornithine ( $\alpha$-difluoromethylornithine) for the treatment of malignant gliomas. CNS Oncol [Internet]. 2018; 7: CNS16. Available at: https://www.futuremedicine.com/doi/10.2217/cns-2017-0031

23. Kuemmerle A, Schmid C, Kande V, et al. Prescription of concomitant medications in patients treated with Nifurtimox Eflornithine Combination Therapy (NECT) for T.b. gambiense second stage sleeping sickness in the Democratic Republic of the Congo. Picado A, Ed. PLoS Negl Trop Dis [Internet]. 2020; 14: e0008028. Available at: https://dx.plos.org/10.1371/journal.pntd.0008028

24. Burri C, Brun R. Eflornithine for the treatment of human African trypanosomiasis. Parasitol Res [Internet]. 2003; 90: S49-52. Available at: http://link.springer.com/10.1007/s00436-0020766-5

25. Beckmann N, Schafferer L, Schrettl M, et al. Characterization of the Link between Ornithine, Arginine, Polyamine and Siderophore Metabolism in Aspergillus fumigatus. Henrique G, Ed. PLoS One [Internet]. 2013; 8: e67426. Available at: https://dx.plos.org/10.1371/journal.pone.0067426

26. Boeke JD, La Croute F, Fink GR. A positive selection for mutants lacking orotidine-5'phosphate decarboxylase activity in yeast: 5-fluoro-orotic acid resistance. Mol Gen Genet MGG [Internet]. 1984; 197: 345-6. Available at: http://link.springer.com/10.1007/BF00330984

27. Kilani J, Fillinger S. Phenylpyrroles: 30 Years, Two Molecules and (Nearly) No Resistance. Front Microbiol [Internet]. 2016; 7: 1-10. Available at: http://journal.frontiersin.org/article/10.3389/fmicb.2016.02014/full

28. Brandhorst TT, Klein BS. Uncertainty surrounding the mechanism and safety of the postharvest fungicide fludioxonil. Food Chem Toxicol [Internet]. 2019; 123: 561-5. Available at: https://linkinghub.elsevier.com/retrieve/pii/S0278691518308391

29. Bigham M, Copes R. Thiomersal in vaccines: Balancing the risk of adverse effects with the 
bioRxiv preprint doi: https://doi org/10.1101/2021.04.19.440472; this version posted April 19, 2021. The copyright holder for this preprint (which was not certified by peer review) is the author/funder, who has granted bioRxiv a license to display the preprint in perpetuity. It is made available under aCC-BY-NC-ND 4.0 International license.

risk of vaccine-preventable disease [Internet]. Vol. 28, Drug Safety. 2005. Available at: http://link.springer.com/10.2165/00002018-200528020-00001

30. Clements CJ. The evidence for the safety of thiomersal in newborn and infant vaccines. Vaccine [Internet]. 2004; 22: 1854-61. Available at: https://linkinghub.elsevier.com/retrieve/pii/S0264410X03008090

31. Magos L, Clarkson TW. Overview of the clinical toxicity of mercury. Ann Clin Biochem [Internet]. 2006; 43: 257-68. Available at: http://acb.sagepub.com/lookup/doi/10.1258/000456306777695654

32. Zhai C, Summer D, Rangger C, Haas H, Haubner R, Decristoforo C. Fusarinine C, a novel siderophore-based bifunctional chelator for radiolabeling with Gallium-68. J Label Compd Radiopharm [Internet]. 2015; 58: 209-14. Available at: http://doi.wiley.com/10.1002/jlcr.3286

33. Pontecorvo G, Roper JA, Chemmons LM, Macdonald KD, Bufton AWJ. The Genetics of Aspergillus nidulans. Adv Genet [Internet]. 1953; 141-238. Available at:

https://linkinghub.elsevier.com/retrieve/pii/S0065266008604083

34. Pfister J, Bata R, Hubmann I, et al. Siderophore Scaffold as Carrier for Antifungal Peptides in Therapy of Aspergillus Fumigatus Infections. J Fungi [Internet]. 2020; 6: 367. Available at: https://www.mdpi.com/2309-608X/6/4/367

35. Ocak M, Helbok A, Rangger C, et al. Comparison of biological stability and metabolism of CCK2 receptor targeting peptides, a collaborative project under COST BM0607. Eur J Nucl Med Mol Imaging [Internet]. 2011; 38: 1426-35. Available at: http://link.springer.com/10.1007/s00259-011-1818-9

36. Skriba A, Pluhacek T, Palyzova A, et al. Early and Non-invasive Diagnosis of Aspergillosis Revealed by Infection Kinetics Monitored in a Rat Model. Front Microbiol [Internet]. 2018; 9: 1-7. Available at: https://www.frontiersin.org/article/10.3389/fmicb.2018.02356/full

37. Schrettl M, Kim HS, Eisendle M, et al. SreA-mediated iron regulation in Aspergillus fumigatus. Mol Microbiol [Internet]. 2008; 70: 27-43. Available at: http://doi.wiley.com/10.1111/j.1365-2958.2008.06376.x

38. Bastos RW, Rossato L, Valero C, Lagrou K, Colombo AL, Goldman GH. Potential of Gallium as an Antifungal Agent. Front Cell Infect Microbiol. 2019; 9: 1-11.

39. Miethke M, Marahiel MA. Siderophore-based iron acquisition and pathogen control. Microbiol Mol Biol Rev [Internet]. 2007; 71: 413-51. Available at:

https://mmbr.asm.org/content/71/3/413

40. Braun V, Pramanik A, Gwinner T, Köberle M, Bohn E. Sideromycins: Tools and antibiotics. BioMetals. 2009; 22: 3-13.

41. Mislin GLA, Schalk IJ. Siderophore-dependent iron uptake systems as gates for antibiotic Trojan horse strategies against Pseudomonas aeruginosa. Metallomics. 2014; 6: 408-20.

42. Gumienna-Kontecka E, Carver PL. Building a Trojan Horse: Siderophore-Drug Conjugates for the Treatment of Infectious Diseases. In: Carver PL, Ed. Essential Metals in Medicine: Therapeutic Use and Toxicity of Metal Ions in the Clinic [Internet]. Berlin, Boston: De Gruyter; 2019: 331-58. Available at: http://www.degruyter.com/view/books/9783110527872/9783110527872-013/9783110527872013.xml

43. Al Shaer D, Al Musaimi O, de la Torre BG, Albericio F. Hydroxamate siderophores: Natural occurrence, chemical synthesis, iron binding affinity and use as Trojan horses against pathogens. Eur J Med Chem [Internet]. 2020; 208: 112791. Available at: https://doi.org/10.1016/j.ejmech.2020.112791

44. Dietl A-M, Misslinger M, Aguiar MM, et al. The Siderophore Transporter Sit1 Determines Susceptibility to the Antifungal VL-2397. Antimicrob Agents Chemother [Internet]. 2019; 63: 1-13. Available at: http://aac.asm.org/lookup/doi/10.1128/AAC.00807-19

45. Chitambar CR. Medical Applications and Toxicities of Gallium Compounds. Int J Environ Res Public Health [Internet]. 2010; 7: 2337-61. Available at: http://www.mdpi.com/16604601/7/5/2337

46. Chitambar CR. Gallium and its competing roles with iron in biological systems. Biochim Biophys Acta - Mol Cell Res [Internet]. 2016; 1863: 2044-53. Available at: 
bioRxiv preprint doi: https://doi org/10.1101/2021.04 19.440472; this version posted April 19, 2021. The copyright holder for this preprint (which was not certified by peer review) is the author/funder, who has granted bioRxiv a license to display the preprint in perpetuity. It is made available under aCC-BY-NC-ND 4.0 International license.

http://dx.doi.org/10.1016/j.bbamcr.2016.04.027

47. Goss CH, Kaneko Y, Khuu L, et al. Gallium disrupts bacterial iron metabolism and has therapeutic effects in mice and humans with lung infections. Sci Transl Med [Internet]. 2018; 10: eaat7520. Available at: https://stm.sciencemag.org/lookup/doi/10.1126/scitranslmed.aat7520

48. Ghosh A, Ghosh M, Niu C, Malouin F, Moellmann U, Miller MJ. Iron transport-mediated drug delivery using mixed-ligand siderophore- $\beta$-lactam conjugates. Chem Biol. 1996; 3: 1011-9.

49. Miller $\mathrm{MJ}, \mathrm{Zhu} \mathrm{H}, \mathrm{Xu} \mathrm{Y}$, et al. Utilization of microbial iron assimilation processes for the development of new antibiotics and inspiration for the design of new anticancer agents. BioMetals [Internet]. 2009; 22: 61-75. Available at: http://link.springer.com/10.1007/s10534008-9185-0

50. Wencewicz TA, Long TE, Möllmann U, Miller MJ. Trihydroxamate SiderophoreFluoroquinolone Conjugates Are Selective Sideromycin Antibiotics that Target Staphylococcus aureus. Bioconjug Chem [Internet]. 2013; 24: 473-86. Available at: http://link.springer.com/10.1007/s10534-008-9185-0

51. Neumann W, Sassone-Corsi M, Raffatellu M, Nolan EM. Esterase-Catalyzed Siderophore Hydrolysis Activates an Enterobactin-Ciprofloxacin Conjugate and Confers Targeted Antibacterial Activity. J Am Chem Soc [Internet]. 2018; 140: 5193-201. Available at: file://C:/Users/Carla Carolina/Desktop/Artigos para acrescentar na qualificação/The impact of birth weight on cardiovascular disease risk in the.pdf

52. Pandey A, Savino C, Ahn SH, Yang Z, Van Lanen SG, Boros E. Theranostic Gallium Siderophore Ciprofloxacin Conjugate with Broad Spectrum Antibiotic Potency. J Med Chem [Internet]. 2019; 62: 9947-60. Available at: https://pubs.acs.org/doi/abs/10.1021/acs.jmedchem.9b01388

53. Glassman PM, Muzykantov VR. Pharmacokinetic and Pharmacodynamic Properties of Drug Delivery Systems. J Pharmacol Exp Ther [Internet]. 2019; 370: 570-80. Available at: http://jpet.aspetjournals.org/lookup/doi/10.1124/jpet.119.257113

54. El-Lababidi RM, Rizk JG. Cefiderocol: A Siderophore Cephalosporin. Ann Pharmacother [Internet]. 2020; 54: 1215-31. Available at: http://journals.sagepub.com/doi/10.1177/1060028020929988

55. Petrik M, Haas H, Dobrozemsky G, et al. 68Ga-Siderophores for PET Imaging of Invasive Pulmonary Aspergillosis: Proof of Principle. J Nucl Med [Internet]. 2010; 51: 639-45. Available at: http://jnm.snmjournals.org/cgi/doi/10.2967/jnumed.109.072462

56. Henneberg S, Hasenberg A, Maurer A, et al. Antibody-guided in vivo imaging of Aspergillus fumigatus lung infections during antifungal azole treatment. Nat Commun [Internet]. 2021; 12: 1707. Available at: http://dx.doi.org/10.1038/s41467-021-21965-z

57. Ferreira K, Hu HY, Fetz V, et al. Multivalent Siderophore-DOTAM Conjugates as Theranostics for Imaging and Treatment of Bacterial Infections. Angew Chemie - Int Ed [Internet]. 2017; 56: 8272-6. Available at: http://doi.wiley.com/10.1002/anie.201701358 